\title{
A blinding headache and two black eyes
}
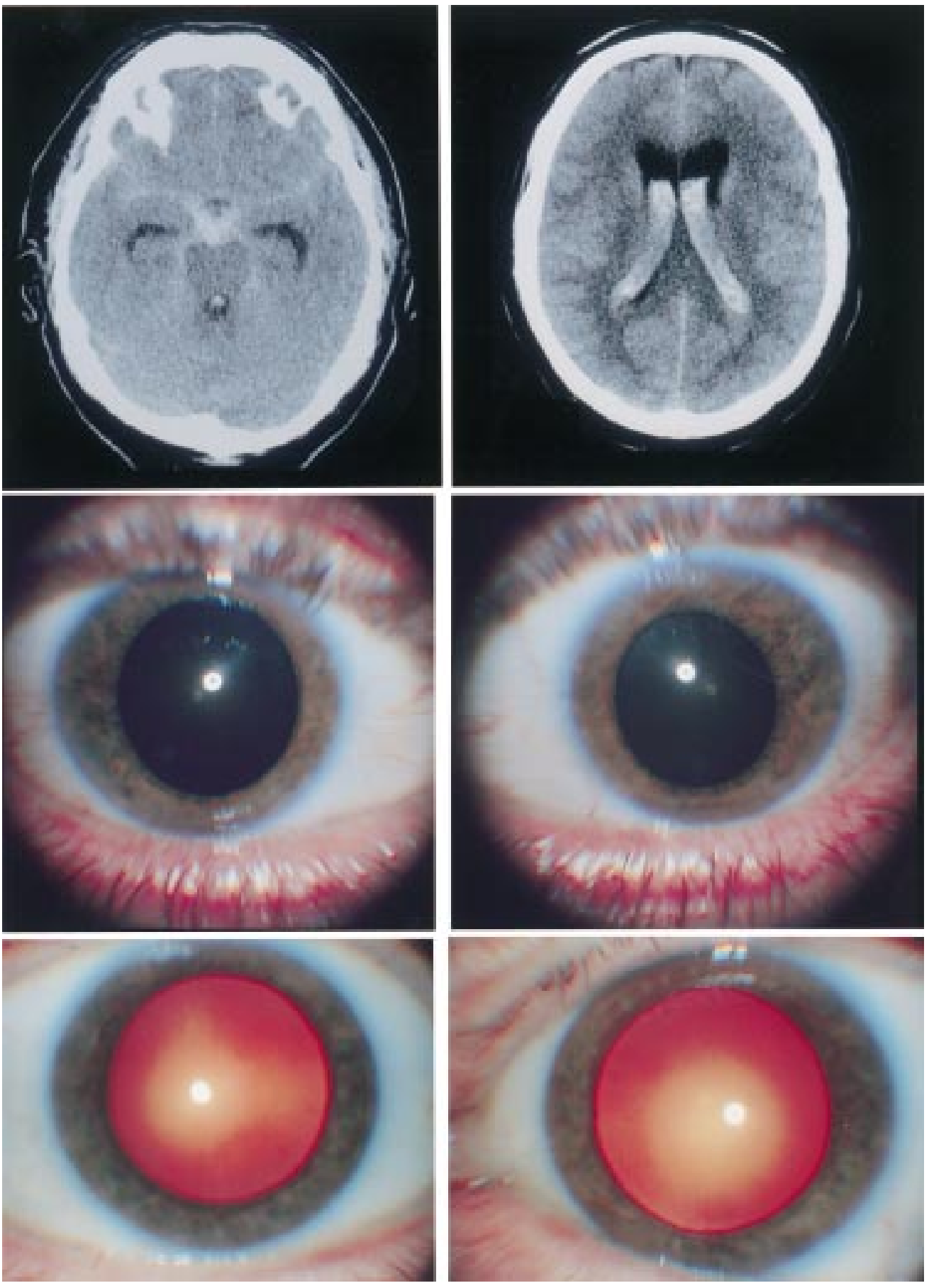

A 54 year old farmer, while bailing hay, recalled a sudden headache, "as if struck by lightening" before he lost consciousness. Brain CT showed widespread subarachnoid and intraventricular blood and acute obstructive hydrocephalus (figure top row).
The visual acuity was limited to detection of motion in both eyes. The red reflex and pupillary responses were absent. The posterior pole of the eye could not be visualised due to extensive vitreous haemorrhage. (Figure middle row: absent red reflex with appearance of "black 
pupils" after maximal dilatation; bottom row: red reflex in a normal subject for comparison.) Retinal haemorrhage in subarachnoid haemorrhage may rupture the hyaloid membrane to enter the vitreous compartment (Terson's syndrome). ${ }^{12}$ Although the prognosis for spontaneous visual recovery is good, vitrectomy should be considered in those patients with bilateral vitreous haemorrhage who have not improved after 6 to 12 months. ${ }^{3}$

NICHOLAS D LAWN

EELCO F M WIJDICKS BRIAN R YOUNGE
Department of Neurology (Neurological-Neurosurgical Intensive Care Unit, Saint Mary's Hospital), and Ophthalmology, Mayo Medical Center, Rochester, MN, USA

Correspondence to: Dr E F M Wijdicks, Department of Neurology (W8A), Mayo Clinic, 200 First Street SW, Rochester, MN 55905, USA. Telephone 0015072845443 fax 001507284 4795; email wijde@mayo.edu

1 Terson A. De l'hemorrhagie dans le corps vitre au cours de l'hemorrhagie cerebrale. La Clinique Ophthalmologique 1900;6:309-12.

2 Pfausler B, Belci R, Metzler R, et al. Terson's syndrome in spontaneous subarachnoid hemorrhage: a prospective study in 60 consecutive patients. F Neurosurg 1996;85:392-4.

3 Schultz PN, Sobol WM, Weingeist TA. Long term visual outcome in Terson's syndrome. Ophthalmology 1991;98: 1814-19.

\section{NEUROLOGICAL PICTURE}

\section{Chronic misuse of paint thinners}

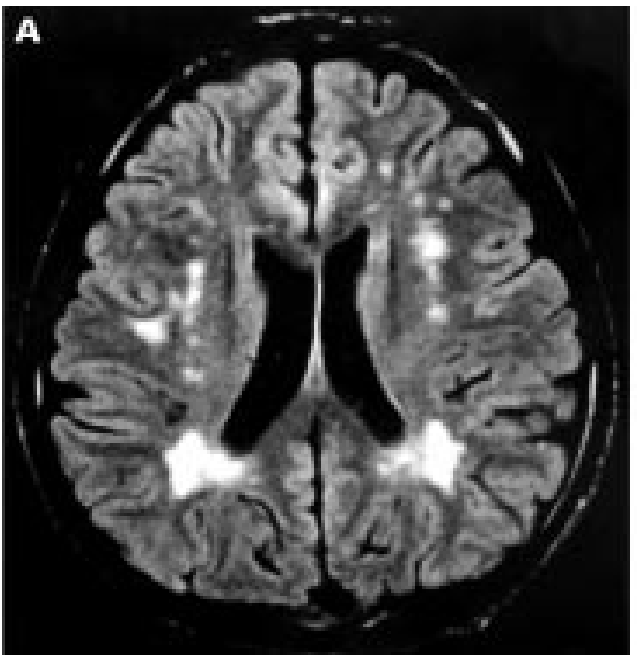

A 17 year old man who had chronically misused paint thinners for 3 years was examined for occasional occipital headache after an abstinence of 4 months. He was neurologically normal without any cognitive or psychological impairment. Fluid attenuated inversion recovery images showed multiple high intensity lesions in the subcortical and deep white matter (figure, A, B).

The major constituent of thinner is toluene, which is a neurotoxic solvent. Brain MRI in chronic thinner or toluene misuse may show cerebral and cerebellar atrophy, atrophy of the corpus callosum, and loss of grey-white matter contrast. T2 weighted images show scattered high signal lesions in the white matter and brainstem due to demyelination or gliosis, and low intensity lesions in the basal ganglia, thalami, and subcortical white matter, which

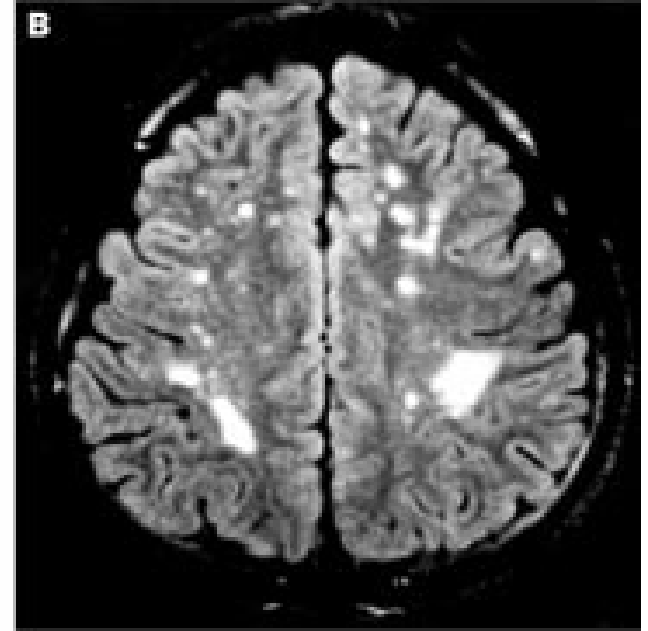

are postulated to be caused by iron deposition or toluene accumulation into the cell membrane due to its lipophilicity. ${ }^{1-3}$

M KOMIYAMA K YAMANAKA

Department of Neurosurgery, Osaka City General Hospital, Osaka, Japan

Correspondence to: Dr M Komiyama, Department of Neurosurgery, Osaka City General Hospital, 2-13-22, Miyakojima-Hondori, Miyakojima, Osaka, 543-0021, Japan Telephone 008166929 1221; fax 008166929 1091; email komiyama@japan-mail.com

1 Caldemeyer KS, Pascuzzi RM, Moran CC, et al. Toluene abuse causing reduced MR signal intensity in the brain abuse causing reduced MR signal inten

2 Rosenberg NL, Kleinschmidt-DeMasters BK, Davis KA, et Rosenberg NL, Kleinschmidt-DeMasters BK, Davis KA, et
al. Toluene abuse causes diffuse central nervous system al. Toluene abuse causes diffuse central nervous
white matter changes. Ann Neurol 1988;23:611-4.

3 Unger E, Alexander A, Fritz T, et al. Toluene abuse: physi$\mathrm{cal}$ basis for hypointensity of the basal ganglia on T2-weighted MR images. Radiology 1994;193:473-6. 